\title{
Análise Sistemática de Utilização de Softwares Educacionais em Biologia no Ensino Médio
}

\author{
Tatiane Fonseca Barbosa ${ }^{1}$, Almir de Oliveira Costa Junior ${ }^{1}$ \\ ${ }^{1}$ Universidade do Estado do Amazonas (UEA) - Escola Superior de Tecnologia (EST) \\ 69050-020 - Manaus - AM - Brasil. \\ $\{$ tfb.inf, adjunior\}@uea.edu.br
}

\begin{abstract}
Educational software's are used in many contexts nowadays, even more so in schools and universities. In this context, this article presents a systematic review of the literature on the use of Educational Software in the discipline of Biology, identifying articles in Portuguese from 2014 to 2018. With a focus on the target audience of secondary education, it was possible to identify the contexts, involved in teaching-learning and reasons for attractiveness. As for the types of assessments was also observed, as well as the points indicate their use for the work associated with the traditional and more involved in relation to the discipline.
\end{abstract}

Resumo. Softwares Educacionais são utilizados em diversos contextos hoje em dia, mais ainda em escolas e universidades. Neste contexto, este artigo apresenta uma revisão sistemática da literatura em torno do uso de Softwares Educacionais na disciplina de Biologia, identificando artigos em português nos periodos de 2014 até 2018. Com foco no público alvo do ensino médio foi possivel identificar os contextos, motivações comumente envolvidas no ensinoaprendizagem e razões por atratividade. Quanto aos tipos de avaliações, também foi observado, os pontos que indicam o seu uso para a trabalho associado ao tradicional e de maior envolvimento em relação à disciplina.

\section{Introdução}

De modo geral, os softwares educacionais tem sido evidenciados cada vez mais no espaço escolar. Sua adesão neste tipo de ambiente, acaba abrindo caminhos para auxiliar os métodos educacionais e fortalecer o processo de ensino e aprendizagem de conteúdos específicos.

Quando levamos em consideração a disciplina de biologia, podemos verificar que ela tem por finalidade, entender a totalidade da vida humana. Seu objetivo, segundo o PCNEM, é tratar do "fenômeno vida em toda sua diversidade de manifestações. Nesta disciplina, existem muitos temas para serem abordados que apresentam uma complexidade ao longo dos bimestres.

Neste sentindo, buscando realizar um mapeamento do cenário nacional, esta revisão sistemática da literatura (RSL) apresenta resultados sobre as finalidades do uso de softwares educacionais na disciplina de biologia no Ensino Médio. Para isto, foi realizado um levantamento da literatura científica de artigos no idioma português, buscando compreender os contextos inseridos, os softwares educacionais utilizados, as formas de avaliações, suas contribuições e finalidades para o ensino e aprendizado. 
VIII Congresso Brasileiro de Informática na Educação (CBIE 2019)

Anais do XXV Workshop de Informática na Escola (WIE 2019)

\section{Metodologia}

Em sua pesquisa, [Kitchenham and Charters 2007], descreve como planejar uma revisão sistemática voltada para Engenharia de Softwares. Ele preconiza que a revisão sistemática pode ser desenvolvida em três etapas: planejamento, condução e relato da revisão.

Os itens a seguir especificam como foi conduzida a pesquisa com base no trabalho de [Kitchenham and Charters 2007].

\subsection{Questões de Pesquisa}

O primeiro passo foi a formulação da pergunta de pesquisa primária na qual originou questões derivadas:

Questão de Pesquisa: Qual o objetivo de se utilizar software educacional na disciplina de Biologia?

QP1: Quais softwares educacionais são mais utilizados?

QP2: Quais são os contextos e público-alvo relatados?

QP3: Quais são as estratégias de avaliação e os resultados relatados?

\subsection{Estratégia de busca}

Utilizando o Google acadêmico, foram realizadas buscas por artigos com as palavraschave ("software educacional" OR "softwares educacionais" OR "biologia"). Os resultados das bases mais relevantes foram organizados através da ferramenta Mendley.

As bases escolhidas para a análise foram: Anais Seminário de Iniciação Científica - SEMIC; Manancial Repositório digital da UFSM; Revista de Ensino de Bioquímica; Simpósio Brasileiro de Informática na Educação - SBIE; Workshop de Informática na Escola - WIE; Workshops do Congresso Brasileiro de Informática na Educação WCBIE; Revista Brasileira de Informática na Educação - RBIE; Revista Novas Tecnologias na Educação - Renote.

Tabela 1. Artigos obtidos a partir da pesquisa nas bases de dados escolhidas

\begin{tabular}{|c|c|c|c|c|c|c|c|c|c|}
\hline Revistas & SEMIC & UFSM & REB & SBIE & WIE & WCBIE & RBIE & Renote & TOTAL \\
\hline $\begin{array}{c}\mathrm{N}^{\mathbf{o}} \mathrm{de} \\
\text { Resultados }\end{array}$ & 12 & 26 & 5 & 23 & 17 & 14 & 13 & 24 & $\mathbf{1 3 4}$ \\
\hline
\end{tabular}

\subsection{Critérios de Pesquisa}

Os critérios de inclusão de artigos foram: i - abordar a disciplina biologia, ii - apresentar a aplicação de softwares educacionais na disciplina e iii - artigos que relatavam contextos no Ensino Médio nos período entre 2014 a 2018. Foram excluídos estudos fora dos critérios de inclusão, estudos duplicados, revisões sistemáticas e estudos não relevantes (excluídos pelo título, resumo, palavras-chave não relacionados aos objetivos desta RSL). Por fim, foi realizada a leitura dos resumos dos artigos, a metodologia e a sessão de resultados.

\subsection{Critérios de Avaliação}

Após a aplicação dos critérios de inclusão e exclusão, o número de artigos foi reduzido para 10. Para este conjunto de artigos foram aplicados os critérios de avaliação que se encontram na tabela 2.

Tabela 2. Critérios para avaliação dos artigos selecionados 
VIII Congresso Brasileiro de Informática na Educação (CBIE 2019)

Anais do XXV Workshop de Informática na Escola (WIE 2019)

\begin{tabular}{|l|}
\hline A1. Qual o objetivo proposto da experiência relatada? \\
\hline A2. Qual foi o público-alvo da experiência? \\
\hline A3. Quais temas de biologias foram abordados? \\
\hline A4. Quais os softwares foram utilizados? \\
\hline A5. Em que ambiente as atividades foram desenvolvidas? \\
\hline A6. Qual a duração das atividades? \\
\hline A7. Quais os métodos/estratégias de avaliação utilizados na experiência? \\
\hline
\end{tabular}

\section{Resultados e Discussões}

Foram levantados dados importantes para responder as questões levantadas no tópico 2.1. A tabela 3 apresenta um resumo das informações obtidas referentes aos critérios de avaliações descritos da tabela 2 .

\subsection{QP1: Quais softwares educacionais são mais utilizados?}

Levando em consideração o critério A1, é possível observar que os trabalhos apresentam objetivos na perspectiva de melhorar o ensino e a aprendizagem, contribuir com mais ferramentas e softwares voltados para a educação, diferenciar aulas ou dinamiza-las, auxiliar professores, analisar impactos causadas através de seu uso e também engajar os alunos em relação às aulas tradicionais.

Para o critério A4, é possível identificar softwares educacionais criados com objetivos de suprir a necessidade nas aulas de biologia, páginas web destinadas ao ensino e atratividade dos alunos, plataformas completas para o estudo de biologia, jogos educacionais, uso de software proprietário usados sob o contexto educacional e até animações e recursos didáticos tecnológicos (slide, vídeos, imagens e simulações).

\subsection{QP2: Quais são os contextos e público-alvo relatados?}

Para responder esta pergunta, o item A2 foi classificado da seguinte forma: somente alunos do Ensino Médio (7), alunos e professores do Ensino Médio (1), em conjunto com alunos do Fundamental e Médio (1) e em conjunto de alunos do Ensino Médio e superior (1).

Não existe um tema mais abordado, pois cada artigo foi direcionado à um tema dentro da disciplina de Biologia. Cerca de 50\% escolheram utilizar grupos variando entre 16 até 152 alunos; 20\% utilizaram grupos variando entre 6 à 8 alunos e $30 \%$ não submeteram a avaliações com alunos (apenas utilizando-os para seu desenvolvimento).

Cerca de $70 \%$, não especificaram a duração de aplicação e/ou desenvolvimento das atividades (A6), (1) afirmou que teve uma duração total de 8 intervenções, (1) afirmou que a duração para construção de seu jogo educacional foi de 8 meses, (1) especificou com detalhes a duração das atividades, detalhando 6 encontros, na qual 3 eram presenciais e 3 a distância. No critério A5, os locais mais utilizados para construção ou aplicações dos softwares educacionais foram: i - os laboratórios de Informática (6), ii - não especificado (2) e iii - própria sala de aula (2).

Por fim, $80 \%$ dos contextos relatados para o uso de softwares educacionais, são para implantação de recurso educacional digital em contrapartida do sistema tradicional de ensino.

\subsection{QP3: Quais são as estratégias de avaliação e os resultados relatados?}

O questionário, apresenta-se como a principal estratégia de avaliação. Outros artigos, 
VIII Congresso Brasileiro de Informática na Educação (CBIE 2019)

Anais do XXV Workshop de Informática na Escola (WIE 2019)

apenas apresentam apenas relatos de experiências de alunos e como eles se sentiram ao utilizar um software educacional e suas motivações. Além disso, houve um estudo de caso na qual comparou-se duas turmas, uma com uso de computadores e outra sem.

Tabela 3. Síntese dos resultados relatados

\begin{tabular}{|c|c|c|}
\hline Trabalhos & Descrição & Resultados \\
\hline $\begin{array}{c}\text { [Borges } \\
\text { 2017] }\end{array}$ & $\begin{array}{l}\text { Utilização do jogo Body para melhorar o } \\
\text { processo de aprendizagem colaborativa e } \\
\text { ativa dos alunos. }\end{array}$ & $\begin{array}{l}\text { Continuidade da implementação para } \\
\text { expansão do jogo. }\end{array}$ \\
\hline $\begin{array}{l}\text { [Corrêa } \\
\text { Taques } \\
\text { Rocha et al. } \\
2018] \\
\end{array}$ & $\begin{array}{l}\text { Pesquisa qualitativa do tipo exploratória } \\
\text { descritiva que buscou investigar as possíveis } \\
\text { contribuições dos diferentes us os de TICs. }\end{array}$ & $\begin{array}{l}\text { As atividades didáticas utilizando os } \\
\text { recursos tecnológicos favoreceu a } \\
\text { aprendizagem dos conteúdos. }\end{array}$ \\
\hline $\begin{array}{c}\text { [Lassen } \\
2014]\end{array}$ & $\begin{array}{l}\text { Apresentar e utilizar softwares Fragata e } \\
\text { NOAS visando proporcionar a dinamização } \\
\text { das aulas como uso de tecnologias e seus re- } \\
\text { cursos. }\end{array}$ & $\begin{array}{l}\text { Os alunos puderamentender o conteúdo } \\
\text { de forma mais objetiva, as sociando as } \\
\text { explicações do professor, com as } \\
\text { visualizações realizadas nos Softwares. }\end{array}$ \\
\hline $\begin{array}{l}\text { [Alcântara et } \\
\text { al. 2015] }\end{array}$ & $\begin{array}{l}\text { Elaborar um aplicativo sobre biomoléculas } \\
\text { para ser utilizado como ferramenta didática } \\
\text { a fim de auxiliar os docentes no ensino de } \\
\text { Bioquímica. }\end{array}$ & $\begin{array}{llr}\text { Interesse dos participantes pelo } \\
\text { aplicativo e pela nova forma de } \\
\text { abordagem dos conteúdos. }\end{array}$ \\
\hline $\begin{array}{l}\text { [Filho and } \\
\text { Filho 2016] }\end{array}$ & $\begin{array}{l}\text { Analisar as contribuições de uma proposta } \\
\text { metodológica de utilização das tecnologias } \\
\text { digitais para trabalhar conceitos de Biologia } \\
\text { no } 3^{\circ} \text { ano do Ensino Médio. }\end{array}$ & $\begin{array}{l}\text { Superação do modelo de simples } \\
\text { memorização de conceitos, aplicação de } \\
\text { técnicas repetitivas e transmissão de } \\
\text { conteúdo. }\end{array}$ \\
\hline $\begin{array}{l}\text { [Adolfo et al. } \\
\text { 2017] }\end{array}$ & $\begin{array}{l}\text { Propor a utilização de recursos tecnológicos } \\
\text { no processo de ensino e aprendizagem da } \\
\text { Biologia a fim de verificar o impacto sobre o } \\
\text { aprendizado dos alunos. }\end{array}$ & $\begin{array}{l}\text { Pôde-se verificar que a utilização das } \\
\text { TICs proporcionou um aprendizado } \\
\text { mais satisfatório, motivando-os e } \\
\text { incentivando-os no processo de } \\
\text { construção de conhecimento. }\end{array}$ \\
\hline $\begin{array}{l}\text { [Coêlho dos } \\
\text { Santos et al. } \\
\text { 2018] }\end{array}$ & $\begin{array}{l}\text { Relata e discute o processo de construção e } \\
\text { aplicação de uma aula sobre Fungos } \\
\text { utilizando o ensino híbrido (sala de aula } \\
\text { invertida) em um Ambiente Virtual de } \\
\text { Ensino e Aprendizagem (AVEA). }\end{array}$ & $\begin{array}{l}\text { O Moodle possibilitou a postagem de } \\
\text { diferentes mídias e a construção de } \\
\text { atividades diversas, como forma de } \\
\text { rompimento ao ensino tradicional. }\end{array}$ \\
\hline $\begin{array}{c}\text { [Mirian } \\
\text { Campos } \\
\text { Tavares } \\
\text { Nascimento } \\
\text { et al. 2014] }\end{array}$ & $\begin{array}{l}\text { Propõe-se a verificar se a produção, } \\
\text { divulgação e uso de um blog educacional } \\
\text { pelos por alunos, pode contribuir para o seu } \\
\text { envolvimento e protagonismo. }\end{array}$ & $\begin{array}{l}\text { Colaborou para o desenvolvimento do } \\
\text { protagonismo juvenil, uma vez que ao } \\
\text { assumir o papel de protagonista na } \\
\text { produção e divulgação da informação } \\
\text { por meio do blog. }\end{array}$ \\
\hline $\begin{array}{l}\text { [Ferreira } \\
\text { Machado et } \\
\text { al. 2018] }\end{array}$ & $\begin{array}{l}\text { Analisar as contribuições das ferramentas de } \\
\text { modelagem molecular. }\end{array}$ & $\begin{array}{l}\text { Os softwares de modelagem molecular } \\
\text { puderam contribuir com a inserção } \\
\text { crítica e reflexiva dessa ferramenta } \\
\text { pelos professores e alunos. }\end{array}$ \\
\hline $\begin{array}{l}\text { [Albuquerque } \\
\text { et al. 2015] }\end{array}$ & $\begin{array}{l}\text { Discute sobre a utilização de recursos que } \\
\text { podem ser utilizados para trabalhar o déficit } \\
\text { na aprendizagem dos estudantes, de modo a } \\
\text { fazer uso de novas formas de aprendizagem } \\
\text { e que desperte o interesse do aluno a ampliar } \\
\text { o dicionário técnico. }\end{array}$ & $\begin{array}{l}\text { Espera-se que o recurso sirva como } \\
\text { complemento aos livros didáticos } \\
\text { convencionais, permitindo } \\
\text { recuperação de dados científicos. }\end{array}$ \\
\hline
\end{tabular}

\section{Conclusão}

Como principal objetivo relatado, identificou-se uma tendência para o uso de softwares educacionais na qual implica a contrapartida em relação ao ensino tradicional, 
como forma de quebrar a ausência de diversidade na sala de aula. As estratégias de avaliação utilizadas nas experiências têm, em sua maioria, explorado questionários, alguns nos formatos pré e pós - para extrair dados que possam ser analisados.

Os resultados obtidos são diversos, mas são promissores no que diz respeito a vontade de melhorar o ensino e a aprendizado, auxiliar os professores na inserção da computação em suas aulas, o compromisso de produzir softwares e páginas web educacionais e pôr fim a tentativa de engajar o aluno nas aulas.

Como trabalhos futuros, espera-se utilizar os aprendizados dessa RSL como ponto de partida para a investigação de como apoiar um ou mais dos perfis identificados.

\section{Referências}

Adolfo, M. D. S., Machado, D. and Warpechowski, M. (2017). "Ensino e Aprendizagem de Biologia no Ensino Médio através da Informática Educativa". In Anais do Workshop de Informática na Escola. . $\quad$ http:/www.brie.org/pub/index.php/wie/article/view/7279, Maio.

Albuquerque, I. C. S. D, Coelho, J. F. R. and Antunes, J. P. L., et al. (2015). "Construção de um dicionário virtual para incremento do aprendizado de Biologia no ensino propedêutico". Revista Brasileira de Informática na Educação, v. 23, n. 03, p. 131.

Alcântara, N. R. D and Filho, A. V. D. M. (2015). "Elaboração e utilização de um aplicativo como ferramenta no ensino de bioquímica: carboidratos, lipídios, proteínas e ácidos nucleicos". Revista de Ensino de Bioquímica, v. 13, n. 3, p. 54-72.

Borges, G. de A. (2017). "Evolução De Um Videogame Educacional Na Área De Fisiologia Humana". Anais Seminário de Iniciação Científica, v. 0, n. 21.

Filho, C. B. L. and Filho, J. A. de C. (2016). "Análise de uma Proposta Metodológica para Uso das Tecnologias Digitais no Ambiente Escolar". In Anais do Workshop de Informática na Escola. . http:/www.br-ie.org/pub/index.php/wie/article/view/6849, Maio.

Kitchenham, B. and Charters, S. (2007). Guidelines for performing Systematic Literature Reviews in Software Engineering. 2.3 ed. Durham.

Lassen, R. S. (2014). "Uso de softwares no processo de ensino e aprendizagem de biologia no ensino médio da Escola Estadual Padre Gonzales". UFSM,

Machado, E. F., Miquelin, A. F. and Gonçalves, M. B. (2018). "A modelagem molecular como mediadora da aprendizagem da estrutura e da função da molécula de DNA". Renote, v. 15, n. 2.

Nascimento, L. M. C. T. and Garcia, L. A.M. (2014). "Promovendo o protagonismo juvenil por meio de blogs e outras redes sociais no Ensino de Biologia". Renote, v. 12, n. 1.

Rocha, J. C. T., Demuner, L., Nobre, A. M. and Nunes, V. B. (2018). "Tic No EnsinoAprendizagem Do Ciclo Da Água: Uma Proposta Transversal No Ensino Médio". Renote, v. 16, n. 1.

Santos, A. C. dos, Nicolete, P. C., Mattiola, N. and Silva, J. B Da. (2018). "Ensino Híbrido: Relato de Experiência sobre o uso de AVEA em uma proposta de Sala de Aula Invertida para o Ensino Médio". Renote, v. 15, n. 2. 